\title{
On Chinese Non-Governmental Organizations' Dilemma and Outlet
}

\author{
Daoming Xia \\ School of Economics \& Management, Changzhou University \\ Changzhou 213164, China \\ E-mail: xdm@cczu.edu.cn
}

\begin{abstract}
During China's modernization process, dramatic changes have been made in Chinese society, bringing about development in non-governmental organizations' living environment involving politics, economy and so on as well as great increase in quantity and type. However, due to imperfect market economy and democratic politics, these organizations' development has been held back by their insufficient capacity and independence. In this article, I try to analyze causes for relevant problems among some internal and external elements and then put forward some suggestions on how to solve them.
\end{abstract}

Keywords: Non-governmental organization, Problem, Countermeasure

\section{The Definition of Non-Governmental Organization and its Development in China}

\subsection{The Definition of Non-Governmental Organization}

Up to now, there has been no universal standard for defining non-governmental organization. Coming from the expression of Non-Governmental Organization, it is abbreviated as NGO.

The expression of Non-Governmental Organization originally came from Article 71 in Charter of the United Nations signed in June 1945, in which it is defined as non-profit and voluntary civil organization organized locally, nationally or internationally.

Lester M. Salamon in Johns Hopkins University of U.S.A (1992) once pointed out a five-feature method, according to which a non-governmental organization should be endowed with the following five features: (1) sense of organization; (2) non-government; (3) non-profit; (4) autonomy; (5) free will. This definition has become a quite classical one in western countries.

There is few non-governmental organization in China totally conforming to western standard. This is the reason why Chinese scholars tend to define this kind of organization with a looser standard by giving corresponding definitions for non-governmental organizations according to their own standards. In my opinion, it is reasonable to define Chinese non-governmental organizations in a loose way, that is, non-profit and legal organizations lying between government and social individuals to offer public services.

\subsection{The Development of China's Non-Governmental Organizations}

China's delayed development in non-governmental organizations is attributed to specific economic and political environment. It is not until the reform and opening up that non-governmental organizations got developed. Since 1990s, with the establishment of Socialist market economy and a goal of "small government, large society", a large number of non-governmental organizations have been established, creating a prosperous situation.

To sum up, since reform and opening up, China's non-governmental organizations have achieved rapid development, mainly manifested in the following aspects: First comes a great increase in number. Up to the end of 2008, there had been 1597 foundations and 414000 social organizations, achieving a leaping increase compared with the very beginning of reform and opening. Second is a greater variety, covering education, science and technology, culture, health care, environmental protection, public welfare, charity and so on. Third is its more significant role in clearing channels for claims, coordinating different parties' benefits, promoting development and improvement of Socialist market economy as well as promoting social welfare and cause of the public good.

\section{Major Problems Facing China's Non-Governmental Organizations}

In spite of the unprecedented development since reform and opening up, China's non-governmental organizations are still faced with many problems due to imperfect construction of market economy and democratic politics. 


\subsection{Poor Internal Management and Self-governing}

Many Chinese non-governmental organizations are established by the department responsible for the work according to government's demands instead of by citizens according to social demands, making quite serious administrative color and bureaucracy. Accordingly members join an organization not out of their agreement on its purpose and mission but taking it as a way to make a living or achieve benefit. Therefore, staff are lacking in passion for their work, enthusiasm or voluntary spirits, leading to low efficiency and poor management level and ability. In most top-down non-governmental organizations, nearly all members are from government departments, many of which are retired government officials while in many bottom-up organizations, there is no fixed personnel channel at all and volunteers are the main force to conduct activities hence seriously influencing their expansion of service items service range, improvement of their service quality, improvement of non-governmental organization's overall ability and their sustainable development (Li, 2008).

Due to insufficient resources, poor ability and lack of self-governing, a large number of non-governmental organizations are in bad need of capital and talents. In addition, due to poor abilities in collecting funds, organization and activities, a vicious cycle is formed. Actually, all these problems are fundamentally due to their poor ability in self-governing. Nowadays, many non-governmental organizations are only empty titles now without colorful activities, powerful leadership and management or necessary funds. Without powerful appeals for the public, their leaders tend to be aged and out-of-date knowledge structure; without fresh blood, their development lies in a standstill state; lacking in new directions and ideas, they rely too much on government organizations and tend to have a tendency for administrative management (Ma, 2008).

\subsection{Poor Self-discipline and Misplaced Goal}

It is the basic method for non-governmental organizations to achieve members' self-management, self-service, self-monitoring and self-protection through their rules and regulations. However, due to its short history, laggard legislation, ineffective government administration and guidance, there is no perfect self-discipline system for non-governmental organizations, leading to violation of laws and rules occasionally, lowering its public trust degree and weakening its ability and basis to serve members. Non-governmental organizations should serve as a bridge between government and enterprises as well as a major organizational form of civil society. But the orientation for such organizations is quite vague or even misplaced, which deviates from its basic feature of "no profit". Some have been changed into economic organizations by pursuing economic benefits for individuals or small groups and some have been changed into political ones by involving themselves too much in politics or being established for political demands.

\subsection{Inadequate Legal Restriction and Incomplete Monitoring System}

This problem is mainly manifested in laggard legislation, inferior legislative level, extensive management and poor correlation with other laws. Up to now, there has been no specific law to standardize and protect social organizations. There is only an administrative regulation Management Rules of Social Organization Registration issued in October 1998 by the State Council. Although there are some articles related to social groups in administrative rules, local laws and rules, there are a lot of shortages in them and many of them lack of operability. It is incomplete laws that have led to the disordered development of social organizations.

At present, there are diversified government monitoring subjects in China. According to Management Rules of Social Organization Registration, civil administration department, department responsible for the work and auditing department are official departments to monitor social groups. Such a special monitoring pattern tends to cause shuffling responsibility and embarrassment and therefore low efficiency; it lacks of monitoring on the normalization of its operation and organization performance; there is no effective quality control system; it lacks of independent third party's monitoring and restriction.

There is no enough social monitoring. The public's civil sense hasn't been formed and the media's monitoring role hasn't been exerted due to its own management system and other social or political reasons.

\subsection{Severely Insufficient Funds}

This is a common and serious problem. Without budgetary allocations for non-governmental organizations, capital becomes a quite serious problem hindering their development. As is shown in a group of data provided in the report A Research on China's NGO: with Individual Cases (2001) as the Center made by NEG Research Center of Public Management College of Tsinghua University, in non-governmental organizations' income structure in 1998, 49.97\% of it came from government's allocations and allowance, much higher than that from enterprises, individuals or foreign institutes. Since government's funds flow to those organizations which have closer relationship with it, a large number of organizations are too lacking in capital to conduct activities 
smoothly or even to lie in a dormant state. There are also some other organizations which implement some operating activities unrelated to their business or even criminal ones in order to survive and develop.

In a word, although non-governmental organizations have become a part of the organizational system of China's modern society, it is still faced with many problems. As a result, some measures should be taken to solve them.

\section{Countermeasures to Solve Problems Related to the Development of China's Non-Governmental Organizations}

\subsection{Properly Dealing with the Relationship with Government}

It is of great significance for non-governmental organizations' activity range, methods and effects to properly deal with the relationship between non-governmental organizations and government. Some pointes should be paid attention to. First, any non-governmental organization has to obey national laws and regulations when implementing any activity, which is a basic principle for it as a social organization as well as an important aspect to distinguish non-governmental organizations with other illegal ones. In China, non-governmental organizations are mainly intended to help government to implement its governing, hence a cooperative and partner-relation relationship. Therefore, they should maintain favorable cooperative relationship with government. Second, they have to be independent, which doesn't mean that they should deviate from government management but that they cannot sacrifice their independence for their sponsors. When organizing daily activities and making major decisions, they should be independent holding to their original missions and values.

\subsection{Perfecting Management System and Improving Human Resources Management}

In this aspect, non-governmental organizations are expected to strengthen their management, to perfect the construction of rules and regulations, to implement organizational management with modern ideas, especially to adopt an open system of financial management and other important issues to enhance their public trust degree.

In addition, some laws and policies should be issued on the employment and social guarantee of NGO staff. Nowadays, it is universally difficult to retain talents in non-governmental organizations due to nonstandard personnel system but poor welfare treatment. In order to solve some relevant problems, it is critical to establish their own human resources management system and relevant institutions and rules and to include them in the whole system of personnel, welfare, social guarantee under the circumstances of market economy, including establishing document management system on non-governmental organizations in talent exchange center and laying down corresponding standards related to NGO's medical treatment insurance, retirement pension, labor insurance and unemployment one as well (Wang, 2007).

\subsection{Speeding up Converting Government's Role}

Government's role has to be converted in order to realize the goal of "small government and large society". To be more specific, those functions which government are not responsible for or are not able to deal with should be transferred to non-governmental organizations in order to give them a chance to serve our society in a fair and open way. Government is expected to offer space and conditions for non-governmental organizations' development as soon as possible. Only by clearly defining government's functions, reducing its direct management and micro management, promoting the transfer from a power-based society to an ability-based one, changing the former single-way control administrative system to a coordinative one and presenting those affairs related to certain industries, the society and public welfare to non-governmental organizations can government's macro-control be enhanced over economic monitoring, maintaining social fairness and non-governmental organizations' role in keeping market orders, compensating for market defaults or government's failures, reducing costs for market transaction, integrating conflicts in social interest be enhanced.

\subsection{Perfecting Monitoring System}

Quality control is the core and laws and regulations are the basis for government to enhance its monitoring on non-governmental organizations' operation. They should be strictly monitored to guarantee their legal operation. Accordingly, social monitoring system should be established to make full use of and enhance social monitoring resources. The public and the media should be the main body for monitoring, especially relevant interest groups, such as donators, objects of services, public citizens, communities, news media as well as social organizations. In addition, public sense of monitoring should be improved, the media's role should be fully exerted and a lot of institutes supporting and monitoring non-governmental organizations should be encouraged. An important measure is to establish an independent third-party assessment institute to perfect the monitoring and restriction on non-governmental organizations and to implement a standardized elimination mechanism. Those ones which are no longer accustomed to the new situation, have poor achievements, have only empty tiles, violate law and regulations or have poor public trust credibility should be removed in a standard way. 


\subsection{Improving Legal Construction}

Basic law of NGO should be issued and specific laws and regulations should be perfected. Based on the basic law on non-governmental organizations, specific legal system on establishing and perfecting folk organizations' registration management should be established to provide guarantee in law and institution for normal activities of non-governmental organizations. In addition, specific laws on registration to economic groups or folk organizations such as foundations or industrial unions as well as to charity groups and pubic funds collection groups should be laid down. Among them, foundations should be greatly distinguished from others since they are public welfare organizations without membership. Therefore, specific laws for them should be established as soon as possible to monitor and manage them.

\subsection{Cultivating Civil Sense and Democratic Idea}

Basically, non-governmental organizations' development relies on highly developed civil society. In the current situation, greater efforts should be made to cultivate a civil society, to enhance democratic atmosphere in order to provide a favorable environment for the development of non-governmental organizations. Only with their civil sense enhanced will people take an active part in politics, which is a process for them to influence politics in certain ways. Political participation is the core of modern democratic politics, a necessary condition for favorable operation of modern political system as well as an important symbol of political modernization and democracy degree. A society with high political participation degree is one in which citizens have favorable cooperation with government, hence providing a good micro environment for the development of non-governmental organizations.

\section{Conclusion}

A variety of problems facing Chinese non-governmental organizations during China's reform and opening up suggest the reality of Chinese society due to different causes from different aspects of our social life. With these causes interwoven with each other, any measure from the perspective of these organizations themselves, government or society will promote these organizations' development and improvement. However, only by pushing reforms in economic system, political system and other systems will all these problems be finally solved and the goal of a civil society be achieved.

\section{References}

Li, Hongyan. (2008). Analysis on Difficulties in Chinese Non-Governmental Organizations' Development. East China Economic Management, (2): p121.

Ma, Jianguo. (2008). On Difficulties in Chinese Non-Governmental Organizations' Development and Government's Governing Elements. Special Zone Economy, (2).

Wang, Xiaojuan. (2007). A Research on Reform in Government Management Policies of Current Chinese Non-Governmental Organizations. Northwest China University. 